[8] Increased Levels of Interleukin 33 in Sera and Synovial Fluid from Patients with Active Rheumatoid Arthritis YASUSHI MATSUYAMA et al The Journal of Rheumatology January 2010, 37 (1) 18-25

[9] Potential involvement of the IL-33-ST2 axis in the pathogenesis of primary Sjogren's syndrome, Ann Rheum Dis, 2014, 73(6): 1259-1263.

[10] The Interleukin 33/ST2 axis in patients with primary Sjogren syndrome: expression in serum and salivary glands, and the clinical association, J Rheumatol, 2015, 42(2): 264-271.

[11] Kok MR, Baum BJ, Tak PP, et al Use of localised gene transfer to develop new treatment strategies for the salivary component of Sjögren's syndrome Annals of the Rheumatic Diseases 2003;62:1038-1046

Acknowledgments: NO

Disclosure of Interests: None declared

DOI: 10.1136/annrheumdis-2020-eular.3433

\section{AB0132 1 ALTERATIONS IN PERIPHERAL T-CELLS AND B-CELLS SUBSETS IN PATIENTS WITH SYSTEMIC LUPUS ERYTHEMATOSUS AND SJÖGREN'S SYNDROME UNDERGOING THERAPEUTIC PLASMA EXCHANGE OR IMMUNOADSORPTION}

Y. Jiang ${ }^{1}$, Q. Wei ${ }^{1}$, Q. Lv ${ }^{1}$, X. Zhang ${ }^{1}$, W. Zhu ${ }^{2}$, J. Gu ${ }^{1} .{ }^{1}$ The Third Affiliated Hospital of Sun Yat-Sen University, Rheumatology and Immunology, Guangzhou, China; 'ªazhou People's Hospital, Gaozhou, China

Background: Systemic lupus erythematosus (SLE) and Sjögren's syndrome (SS) are systemic autoimmune diseases characterized by a broad spectrum of clinical manifestations and disease course. Alternative therapies such as therapeutic plasma exchange (TPE), immunoadsorption are recommended to the patients who lack a good response to standard therapy [1].

Objectives: Our observational study was to explored whether abnormalities in T-cells, B-cells and their subtypes were present in the patients who had TPE or immunoadsorption in patients with SLE and SS compared with healthy controls $(\mathrm{HC})$.

Methods: Demographic, clinical variables and autoantibodies were recorded. Flow cytometry was used to establish the frequencies of lineage subsets. Monoclonal antibodies against 21 surface markers such as CD3, CD4, CD8, were used to distinguish and evaluate T-cells' and B-cells' subpopulation. SLE acvity was measured using systemic lupus erythematosus disease activity index (SLEDAI). Comparisons between subgroups were undertaken using paired T-test, Mann-Whitney $U$ test and ANOVA.
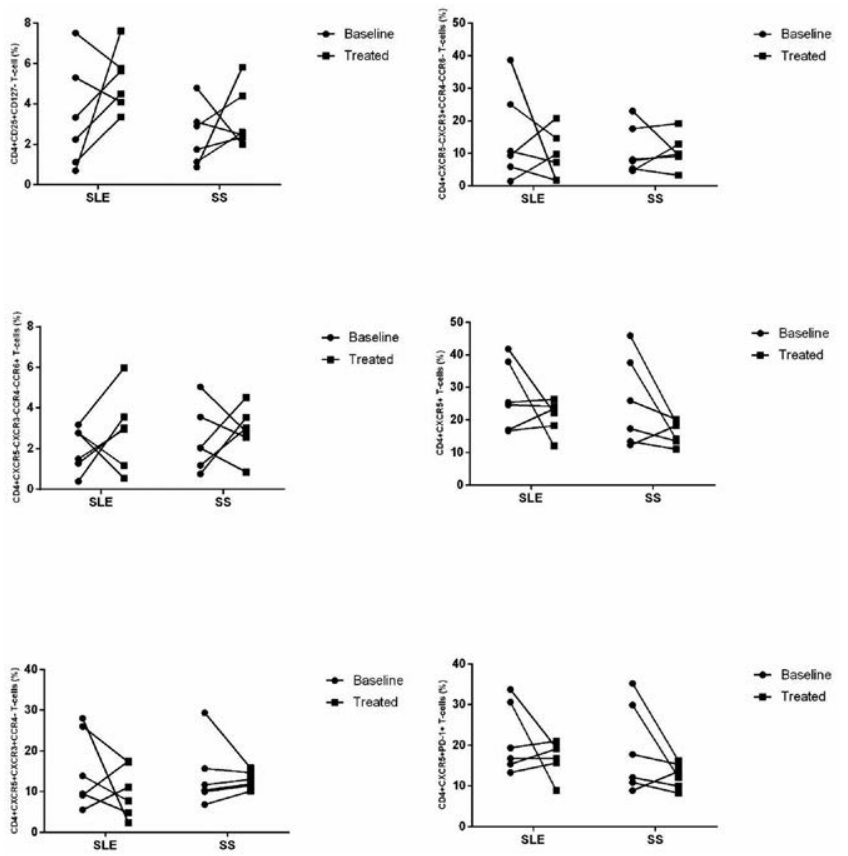

Figure 1. Altered expression of CD4+ T-cell subsets in the patients with SLE and SS after treated with plasma exchange or immunoadsorption

Results: 6 SS patients and 1 SLE patient underwent immune adsorption, while the other 5 SLE patients had plasma exchange all for three times. There was no significant difference among SLE, SS and HC in the proportion of T-cells and B-cells. The proportion of CD3-CD19+CD27+lgD+ B-cells were reduced in SLE, while CD3+CD4+CD25+CD127- T-cells were elevated in SS. The proportion of CD3+CD4+CD45RA+CCR7+T-cells were increased $(p=0.045)$, while CD3+CD4+CD25+CD127- T-cells were declined $(p=0.027)$ and CD3+CD4+CXCR5+PD-1+ T-cells went down after the therapies ( $p \leq$ $0.030)$. The proportion of CD3-CD19+lgD-IgM-CD27+CD38+ B-cells was also reduced after TPE or immunoadsorption $(p=0.032)$ with ANA titers and IgG decreasing dramatically. SLEDAI scores were reduced after the therapy in SLE patients.

Conclusion: The T-cell and B-cell's profiles were proved to have alteration after TPE or immunoadsorption which shed light on the complicated mechanisms of these relatively novel therapy in SLE and SS.

References:

[1] Bertsias GK, Tektonidou M, Amoura Z, et al. Joint European League Against Rheumatism and European Renal Association-European Dialysis and Transplant Association (EULAR/ERA-EDTA) recommendations for the management of adult and paediatric lupus nephritis. ANN RHEUM DIS 2012;71:1771-1782

Acknowledgments: None.

Disclosure of Interests: None declared

DOI: 10.1136/annrheumdis-2020-eular.725

\begin{tabular}{l|l|}
\hline AB0133 & INCREASED SOLUBLE SEMAPHORIN 4D/CD100 IN \\
THE PLASMA OF SJÖGREN'S SYNDROME AND ITS \\
EFFECTS ON HUMAN SALIVARY GLAND CELL AND \\
CD4+ T CELL
\end{tabular}

S. E. Kang ${ }^{1}$, S. U. Kim ${ }^{1}$, R. H. Kim ${ }^{1}$, H. J. Yoo ${ }^{2}$, Y. J. Lee ${ }^{3}$, I. A. Choi ${ }^{4}$, J. K. Park ${ }^{2}$, E. Y. Lee ${ }^{2}$, Y. W. Song ${ }^{1,2}{ }^{1}$ Department of Molecular Medicine and Biopharmaceutical Sciences, Graduate School of Convergence Science and Technology, Seoul National University, Seoul, Korea, Rep. of (South Korea); ${ }^{2}$ Division of Rheumatology, Department of Internal Medicine, Seoul National University Hospital, Seoul, Korea, Rep. of (South Korea): ${ }^{3}$ Division of Rheumatology, Department of Internal Medicine, Seoul National University Bundang Hospital, Seoul, Korea, Rep. of (South Korea); ${ }^{4}$ Division of Rheumatology, Department of Internal Medicine, Chungbuk National University Hospital, Seoul, Korea, Rep. of (South Korea)

Background: Semaphorin 4D (SEMA4D) / CD100, known as a subfamily of axonal guidance proteins, has also been reported to act as an immunoregu lator in several infectious and inflammatory diseases [1]. Sjögren's syndrome (SS) is a systemic autoimmune disease that primarily affects the exocrine glands by infiltrated lymphocytes resulting in dryness of mouth and eyes. $\mathrm{IL}-17$ was reported to impair the integrity of tight junction barrier and attenuate the expression of aquaporin 5 (AQP5), causing salivary gland dysfunction in SS [2].

Objectives: This study was aimed to evaluate the role of SEMA4D in patients with SS and investigate the effect of SEMA4D on human salivary gland epithelial cell (SGEC) and T cell.

Methods: Soluble SEMA4D levels in plasma were measured by enzymelinked immunosorbent assay (ELISA) from patients with SS, non-SS sicca and healthy controls. Immortalized human SGECs, originated from acini (NS-SV-AC) and duct (NS-SV-DC), were used to evaluate the effects of SEMA4D. CD4 ${ }^{+} \mathrm{T}$ cells from human peripheral blood were isolated to determine the secretion of cytokines in response to SEMA4D. IFN- $\gamma$ and IL-17 were used to determine the effects on AQP5 expression of SGEC.

Results: The levels of soluble SEMA4D in plasma were increased in patients with SS (median [interquartile range]: 1221.3 [393.5] pg/mL) com pared to non-SS sicca $(940.2[355.1] \mathrm{pg} / \mathrm{mL}, p=0.006)$ or healthy controls (909.5 [108.0] pg/mL, $p<0.0001)$. The levels of soluble SEMA4D in plasma were correlated with the levels of several autoantibodies including anti-SSA (Spearman's rho $=0.358, p=0.006$ ), anti-SSB (rho $=0.350, p=0.007$ ), and anti-muscarinic receptor 3 (M3R) Ab (rho $=0.495, p<0.001$ ), and also correlated with total IgG ( $r$ o $=0.431, p=0.002$ ). SEMA4D-stimulated SGECs showed decreased expression of tight junctions such as occludin and Zo-1. $\mathrm{CD}^{+} \mathrm{T}$ cells secreted IFN- $\gamma(p=0.025)$, IL-17 $(p=0.028)$, and IL-21 ( $p=$ 0.007 ) with SEMA4D stimulation. IFN- $\gamma$ and IL-17 decreased AQP5 expression in SGECS.

Conclusion: SEMA4D contributed to decreased expression of tight junction in SGECs. SEMA4D induced production of IFN- $\gamma$ and IL-17 in $\mathrm{CD}^{+}{ }^{+} \mathrm{T}$ cells and these cytokine decreased AQP5 expression in SGECs.

References:

[1] Worzfeld T, Offermanns S. Nat Rev Drug Discov. 2014;13(8):603-21.

[2] Bhattarai KR, Junjappa R, Handigund M, Kim HR, Chae HJ. Autoimmun Rev. 2018;17(4):376-90.

Disclosure of Interests: None declared

DOI: 10.1136/annrheumdis-2020-eular.5162 